\title{
HYDROPHOBIC IMPREGNATION OF GEOPOLYMER COMPOSITE BY ETHOXYSILANES
}

\author{
ZDENĚK MAŠEK*, LINDA DiBLÍKOVÁ
}

\author{
Výzkumný a zkušební letecký ústav - Composite Technologies department, Beranových 130, 19005 Prague, \\ Czech Republic \\ * corresponding author: zdenek.masek@vzlu.cz
}

\begin{abstract}
A geopolymer composite was impregnated by incorporating the hydrophobic alkyl group on the outer surface and in the inner structure of the geopolymer. Ethoxysilanes $1 \mathrm{H}, 1 \mathrm{H}, 2 \mathrm{H}, 2 \mathrm{H}$ perfluoroctyltriethoxysilane and hexadecyltrimethoxysilane were used as the source of hydrophobic groups.

Three types of solutions based on the ethoxysilanes were prepared according to adapted procedures. The modification of the geopolymer composites was done by their immersion into the hydrophobic solutions followed by drying at a laboratory or elevated temperature. The effectivity of the procedure was evaluated by measuring the water contact angle on the surface of the modified composite and by measuring the water uptake and stiffness of the composite.

The results confirmed that the silanes hydrolyzed in sol containing $\mathrm{SiO}_{2}$ nanoparticles have a higher hydrophobization effect than solutions of simply hydrolyzed silanes. The resulting impregnation procedure led to the change of the geopolymer composite surface from hydrophilic to hydrophobic.
\end{abstract}

KEYWORDS: geopolymer; sol; hydrophobicity; alkyltrisilane; tetraethoxysilane; contanct angle.

\section{INTRODUCTION}

Geopolymers are alkaline amorphous inorganic polymers, which belong to the group of aluminosilicates 1 . The polymeric spatial structure of geopolymers is created by silicon and aluminium atoms, which are coordinated by atoms of oxygen. Oxygen atoms serve as a bridge connecting the silicon and aluminum atoms. The bridges are created by a condensation of $\left(\mathrm{AlO}_{2}\right)_{-}$ or $\left(\mathrm{SiO}_{4}\right)_{4}-$ anions and poly-anions. Uncondensated $-\mathrm{OH}$ and $-\mathrm{O}-$ groups are the reason of the hydrophilic character of the geopolymer

The geopolymer is in its nature similar to concrete, which means that it is possible to describe the level of protection against a water penetration into geopolymers with similar nomenclature as for concrete structures. It can be divided into three groups [2]: i) protective coating, ii) impregnation and iii) hydrophobic impregnation. The protective coating forms an impermeable layer only on the surface. The impregnation uses special agents, which penetrate into the inner structure of the material and fill the pores. On the contrary, a hydrophobic impregnation does not affect pores, i.e. it acts only as a water repellent. An inappropriate application of the penetration could cause harmful stress and damage to the treated material. Therefore, the hydrophobic impregnation is a widely researched area in the field of conservation and restauration of monuments, because it is material friendly [3, 4]. The hydrophobic impregnation of geopolymers is presented in this paper.

The geopolymer is a microporous material, which can be used as a matrix in fine carbon fibers reinforced composites. However, such composite is usually more porous than the original geopolymer, because of a low adhesion between the matrix and the surface of fibers and an insufficient penetration of the matrix into the unidirectional bundles of carbon fibers. This fact, together with the hydrophilic character of the geopolymer matrix, makes the final composite very sensitive to humidity.

Duan et al. 5 proposed the hydrophobic impregnation of a geopolymer by attaching the molecules of a palmitic acid into its structure by esterification. To our knowledge, this is the only treatment used for geopolymers. Other treatments providing hydrophobic effect were tested on different types of materials, although, in principle, they can be applied also on geopolymers.

It is well known that a small addition of alkyltrialkoxysilanes to the suspension of $\mathrm{SiO}_{2}$ nanoparticles during a surface treatment of textiles increases its hydrophobicity 6 6 9]. Similarly, polydopamine is used as the carrier of hydrophobic groups created by the hydrolysis of alkyltriethoxysilane [10]. In both cases, the formation of nanoparticles with attached hydrophobic groups originating from alkyltriethoxysilanes was observed. A preparation process of binder-based on sol-gel nanoparticles was described in the field of a zinc-silicate anticorrosive coating. These binders are usually prepared by the hydrolysis and condensation of polyethoxysilicates and boric acid in a non-aqueous environment 10. All stated examples of sols represent the concept of carrier nanoparticles with an ability to be attached to a specific substrate, to react with alkyltriethoxysilanes and to affect the hydrophobic properties of the surface treatment. 

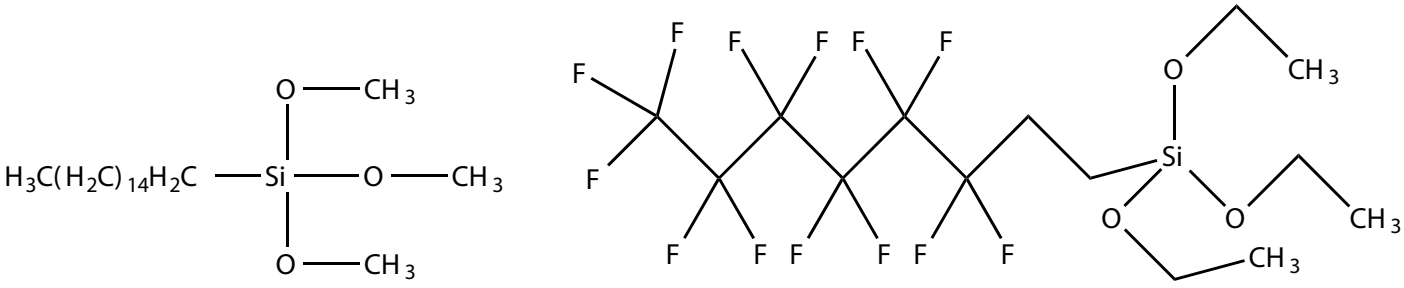

Figure 1. Chemical formula of: (left) $1 \mathrm{H}, 1 \mathrm{H}, 2 \mathrm{H}, 2 \mathrm{H}$-perfluoroctyltriethoxysilane, (right) hexadecyltrimethoxysilane.

The main principle of hydrophobic impregnation in our work is the exposure of the geopolymer composite by a reagent, which is created by acidic hydrolysis of tetraethoxysilane with a small addition of hexadecyltriethoxysilane or $1 \mathrm{H}, 1 \mathrm{H}, 2 \mathrm{H}, 2 \mathrm{H}-$ perfluoroctyltrimethoxysilane. These reagents are probably condensating with hydrophilic $\mathrm{OH}-$ and Ogroups and are usually used together with carrier nanoparticles. The objective of this work is to design a gentle treatment of carbon fiber/geopolymer composite, which will improve its negative properties given by a combination of porosity and hydrophilic character of a geopolymer resin.

\section{MATERIALS AND METHODS}

\subsection{Preparation of GeOPOLYMER RESIN AND COMPOSITE SAMPLES}

The geopolymer resin was prepared by an alkaline activation of a burnt clay shell Mefisto L05 (České lupkové závody, a.s., Czech Republic) and amorphous silica (Thermal silica, Saint-Gobain, France). The alkaline activator of the reaction was an aqueous solution of potassium silicate DV 1.7 (Vodní sklo, a.s., Czech Republic). The mixture was homogenized by Dispermat CA60-M1 (VMA-GETZMANN GmbH, Germany) in a ratio ensuring the best strength properties of the pure geopolymer resin; the exact chemical composition of the resin is a classified information within the project. The mixing vessel was placed in a water chilled container. Firstly, the amorphous silica was mixed with the chilled solution $\left(3{ }^{\circ} \mathrm{C}\right)$ of potassium silicate at $9600 \mathrm{rpm}$ for $20 \mathrm{~min}$. Then, the mixture was cooled at $-20^{\circ} \mathrm{C}$ for $20 \mathrm{~min}$ and metakaolin was added under continuous stirring at $9600 \mathrm{rpm}$ for $5.5 \mathrm{~min}$. Finally, the mixture was left in the freezer for $10 \mathrm{~min}$ and degassed by stirring under vacuum.

The geopolymer composite was prepared by a lamination of 10 layers of carbon fibers fabric in a form of a plain weave, with a density of $93 \mathrm{~g} \mathrm{~cm}^{-2}, 1 \mathrm{~K}$ (Havel Composite CZ s.r.o.). The manual lamination was done using a metal spatula at a dosage of $282 \mathrm{~g}$ resin per square metre of the fabric. The fabric with the geopolymer was layered and pressed by a roller. The last layer was covered by a separation foil with P3 perforation and a non-woven staple. The whole panel was sealed by a PP foil and cured under vacuum at $23^{\circ} \mathrm{C}$ for 72 hours. Finally, test samples with dimensions of $10 \times 8 \times 1.7 \mathrm{~mm}$ were cut from the panel and left at a laboratory temperature for 14 days.

\subsection{PREPARATION OF HYDROPhOBIC SOLUTIONS AND IMPREGNATION OF SAMPLES}

Four types of impregnation agents were used: i) $1 \mathrm{H}, 1 \mathrm{H}, 2 \mathrm{H}, 2 \mathrm{H}$-perfluoroctyltriethoxysilane was purchased under the product name Dynasylan F-8261, ii) hexadecyltrimethoxysilane under the name Dynasylan 9116, iii) tetraethoxysilane under the name Dynasylan A and iv) polyethoxysilane, which contains from three to seven ethoxysilanes units and is produced by a partial hydrolysis, was purchased under the product name Dynasylan 40 (Evonik Industries). The chemical structure of Dynasylan F-8261 and 9116 is displayed in Figure 1 .

Six hydrophobic solutions were prepared from the agents and labelled as A, B, C, D, E and F. Solutions A and $\mathrm{D}$ were mixed according to the application manual of the glass and ceramic materials manufacturer. The preparation of solutions B and E was performed by a modified procedure for cotton fabrics published in [3. We used isopropyl alcohol instead of ethanol and adjusted the dosage of silane. Solutions $\mathrm{C}$ and F were synthesized based on a procedure for the binder of zinc-silicate paint [11. We used the idea of the PEOS hydrolysis in a non-aqueous solution and we improved it by adding alkysilanes.

The solution A was prepared by mixing the PFOTEOS with isopropanol in a weight ratio $1: 99$. One hundred grams of the solution was mixed with $10 \mathrm{~g}$ of distilled water and $0.2 \mathrm{~g}$ of $37 \% \mathrm{HCl}$. The whole mixture was stirred at $500 \mathrm{rpm}$ for 5 hours. Samples were immersed into the solution for 1 hour, wiped by a linen cloth and placed in a drying oven at $105^{\circ} \mathrm{C}$ for 20 hours.

The solution B was obtained by stirring $35 \mathrm{~g}$ of distilled water and $39.45 \mathrm{~g}$ of isopropanol at $500 \mathrm{rpm}$, then $7 \mathrm{ml}$ of $0.01 \mathrm{M} \mathrm{HCl}$ was added. Consequently, $15.65 \mathrm{~g}$ of TEOS was added dropwise under a vigorous stirring at $1000 \mathrm{rpm}$. After each addition of TEOS, the solution became opalescent. Next part of TEOS was always added after the solution had cleared. When the whole amount of TEOS was added, $5.47 \mathrm{~g}$ of PFOTEOS was added dropwise and the obtained colloidal suspension was stabilized by stirring at $500 \mathrm{rpm}$ for $30 \mathrm{~min}$. At the end, samples were immersed into the solution for $30 \mathrm{~min}$, wiped by a linen cloth and dried at $80^{\circ} \mathrm{C}$ for 20 hours.

The solution $\mathrm{C}$ was prepared by hydrolysis and a condensation of PEOS. The reaction was carried out 
in the solution of isopropanol and 2-ethoxyethanol in the presence of boric acid. $49.4 \mathrm{~g}$ of PEOS was mixed with $16.7 \mathrm{~g}$ of isopropanol, $11.1 \mathrm{~g}$ of 2-ethoxyethanol and $4.1 \mathrm{~g}$ of boric acid was added. The reaction mixture was stirred for 1 hour under vacuum with reflux. Then, $18.6 \mathrm{~g}$ of PFOTEOS was added and stirred at a boiling temperature in a reflux configuration for 1 hour. Samples were immersed into this solution at $80^{\circ} \mathrm{C}$ for 2 hours, wiped by a linen cloth and kept at a laboratory temperature for 2 days. Finally, they were dried at $80^{\circ} \mathrm{C}$ for 6 hours.

The solution $\mathrm{D}$ was obtained by the same procedure as the solution A, except that HDTEOS was used instead of PFOTOES as the hydrophobic agent.

The solution E was obtained by stirring $35 \mathrm{~g}$ of distilled water and $39.4 \mathrm{~g}$ of isopropanol at $500 \mathrm{rpm}$ and adding $15 \mathrm{ml}$ of $0.01 \mathrm{M} \mathrm{HCl}$. Then, $10.26 \mathrm{~g}$ of TEOS was added dropwise under an intensive stirring at $1000 \mathrm{rpm}$. After each addition of TEOS, the solution became milky. Next part of TEOS was always added after the solution had cleared. When the whole amount of TEOS was added, $4.0 \mathrm{~g}$ of HDTEOS was dropwise added and the obtained colloidal suspension was stabilized by stirring at $500 \mathrm{rpm}$ for $30 \mathrm{~min}$. At the end, samples were immersed into the solution for $30 \mathrm{~min}$, wiped by a linen cloth and dried at $80{ }^{\circ} \mathrm{C}$ for 20 hours.

The solution $\mathrm{F}$ was prepared by the same procedure as solution C, except that $18.6 \mathrm{~g}$ of HDTEOS was added instead of $18.6 \mathrm{~g}$ of PFTEOS.

In summary, solutions A and D were not based on $\mathrm{SiO}_{2}$ sol. Solutions $\mathrm{B}$ and $\mathrm{E}$ were $\mathrm{SiO}_{2}$ sol solutions. And solutions $\mathrm{C}$ and $\mathrm{E}$ were non-aqueous solutions with $\mathrm{SiO}_{2}$ sol and $\mathrm{H}_{3} \mathrm{BO}_{3}$.

\subsection{Testing of hydrophobic AgEnts' EFFECTIVITY}

Prior to water uptake measurements, the samples were dried at $80^{\circ} \mathrm{C}$ for 4 hours and then at a temperature ramp from 80 to $170^{\circ} \mathrm{C}$ for 16 hours. Water sorption of distilled water was measured during the sample immersion by weighting in time until saturation reached the equilibrium. The sorption was measured with 5, 50 or $100 \mathrm{~mm}$ water column height, where the water column means water level in a beaker. The samples were dried at $100^{\circ} \mathrm{C}$. Three samples were used for each experiment and the average value was calculated.

Water vapour sorption was tested by placing samples into a closed glass container, where a water vapour was generated by heating water to a boiling point $\left(100^{\circ} \mathrm{C}\right)$ and maintaining the conditions for 24 hours. Before the test, the samples were dried at $80^{\circ} \mathrm{C}$ for 4 hours and then at a temperature ramp from 80 to $170{ }^{\circ} \mathrm{C}$ for 16 hours. Three samples were used for each experiment and the average value was calculated.

The surface of the geopolymer composite was analysed by contact angle measurements (CAM) using Surface Energy Evaluation System (Advex Instruments s.r.o., CZ) based on the sessile-drop method

\begin{tabular}{|c|c|c|c|}
\hline \multirow{2}{*}{$\begin{array}{c}\text { Impregnation } \\
\text { solution }\end{array}$} & \multirow{2}{*}{$\begin{array}{l}\text { Contact } \\
\text { angle }\left[^{\circ}\right]\end{array}$} & \multicolumn{2}{|c|}{$\begin{array}{c}\text { Storage } \\
\text { modulus }[\mathrm{GPa}]\end{array}$} \\
\hline & & Before & After \\
\hline none & 0 & 21.5 & 19.0 \\
\hline $\mathrm{A}$ & 70 & 23.6 & 19.4 \\
\hline B & 123 & 24.5 & 20.9 \\
\hline $\mathrm{C}$ & 98 & 24.0 & 21.1 \\
\hline $\mathrm{D}$ & 0 & 23.0 & 19.7 \\
\hline $\mathrm{E}$ & 105 & 25.0 & 21.9 \\
\hline $\mathrm{F}$ & 87 & 24.3 & 22.8 \\
\hline
\end{tabular}

TABle 1. Contact angle and storage modulus before and after impregnation.

and equipped with 2 Mpix $(1600 \times 1200)$ UVC camera. Water was used as the test liquid; the volume of its droplets was $1.5 \mu \mathrm{L}$. The contact angle $(\mathrm{CA})$ is defined as the angle between the specimen surface and the tangent to the droplet surface at the interface of three phases (specimen surface, droplet and ambient air). The $\mathrm{CA}$ was calculated as the average value of 5 measurements for each sample; the calculated standard deviation was lower than 9 for all impregnations. Image analyses was performed using the SEE system software.

The influence on mechanical properties of the composite was investigated as well. Non-destructive measurement of the storage modulus was performed using a DMA Q800 (TA Instruments, USA) at a frequency of $1 \mathrm{~Hz}$ and a strain amplitude of $20 \mu \mathrm{m}$. The storage modulus is the real part of the complex modulus of elasticity and is related to the sample's stiffness.

\section{Results AND Discussion}

\subsection{EFFECT OF TREATMENTS ON CONTACT ANGLE AND STORAGE MODULUS}

Water contact angles stated in Table 1 show that all hydrophobic treatments except D had a significant effect on the increase of the angle when compared to the sample without an impregnation. The treatment in solutions B, C and E changed the surface properties of the geopolymer composite from hydrophilic to hydrophobic, i.e., the $\mathrm{CA}$ was greater than $90^{\circ}$, which is the value determining the transition between hydrophilicity and hydrophobicity. Figure 2 displays the contact angle measurement for the most hydrophobic surface impregnated by a solution based on PFOTEOS with $\mathrm{SiO}_{2}$ sol. The CA of samples E and D could not be measured exactly, because of a very fast absorption of the water drop. Regarding the storage modulus, the impregnation led to a small reduction in stiffness. The decrease of storage modulus for a sample without penetration was caused by a time lag between measurements, which indicates the behaviour of the composite itself. 


\begin{tabular}{|c|c|c|c|c|c|c|c|c|}
\hline \multirow{2}{*}{$\begin{array}{c}\text { Impregnation } \\
\text { solution }\end{array}$} & \multicolumn{2}{|c|}{ Wt. gain [\%] } & \multicolumn{3}{|c|}{ Contact angle $\left[{ }^{\circ}\right]$} & \multicolumn{3}{|c|}{ Storage modulus [GPa] } \\
\hline & Water & Vapor & Before test & Water & Vapor & Before test & Water & Vapor \\
\hline none & 3.4 & 7.2 & 0 & 0 & 0 & 21.0 & 6.4 & 15.3 \\
\hline B & 4.3 & 5.7 & 123 & 126 & 81 & 19.0 & 12.0 & 18.5 \\
\hline $\mathrm{C}$ & 3.2 & 6.9 & 98 & 102 & 85 & 19.5 & 10.4 & 16.9 \\
\hline $\mathrm{E}$ & 3.2 & 5.7 & 105 & 107 & 75 & 21.9 & 12.2 & 17.6 \\
\hline
\end{tabular}

TABLE 2. Changes of composites properties after the tests of water uptake and water vapour sorption.

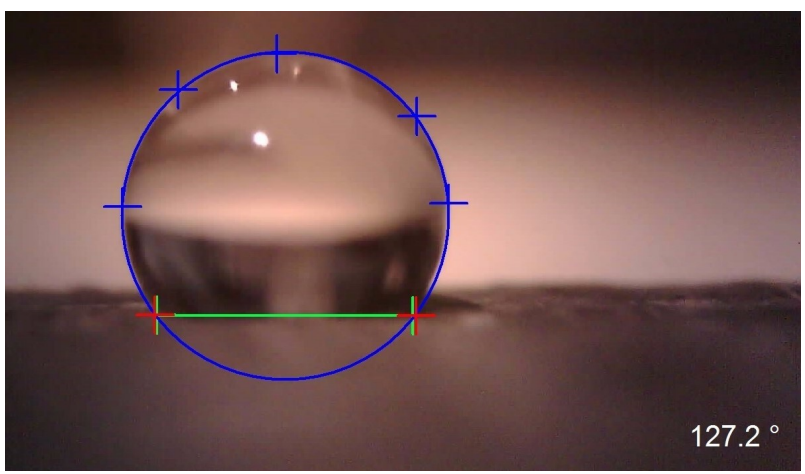

Figure 2. Analysis of a water drop on the surface of geopolymer composite impregnated by solution B; SEE system software image.

\subsection{Change of Composites properties DUE TO WATER UPTAKE AND SORPTION OF WATER VAPOR}

The function of hydrophobic impregnation was evaluated by the tests of water uptake and water vapour sorption. It was observed that the height of the water column, i.e. a submersion depth of samples, had no influence on the water uptake rate of both the impregnated and unimpregnated samples. The saturation of samples reached the equilibrium after 25 hours. All samples, including the unpenetrated one, showed a similar water uptake between 3.2 and $4.3 \%$ when expressed as a weight gain as can be seen in Table 2 Other data stated in the table show that the impregnation effect was not influenced by an exposure to water. Contrary, the hot water vapour caused a distinctive decrease of an average contact angle under $90^{\circ}$. Regarding mechanical properties, storage modulus decreased only slightly after the vapour sorption test. In both cases, the decrease of storage modulus was lower for impregnated samples.

Thus, the results show that the modification of geopolymer composite samples belongs to the category of hydrophobic impregnation, which means that it doesn't prevent moisture penetration, but repels liquid water and allows a diffusion of air humidity.

It should also be noted that the geopolymer tend to generate free alkali and white efflorescence of alkali carbonates on the surface. However, no traces of the efflorescence were observed on the surface of our samples after three months during which they were stored at a laboratory temperature $\left(23^{\circ} \mathrm{C}\right)$ and at a relative humidity in the range of 35 to $50 \%$, and not even after the exposition in extremely humid environment - saturated steam at $100^{\circ} \mathrm{C}$ for 24 hours.

\section{Conclusion}

Our results show that we have successfully modified a hydrophobic treatment for a cotton fabric and applied it on a geopolymer composite. By the application of the hydrophobic agent $1 \mathrm{H}, 1 \mathrm{H}, 2 \mathrm{H}, 2 \mathrm{H}-$ perfluoroctyltriethoxysilane (PFOTEOS) in the form of a solution prepared by hydrolysis and condensation of the silane in fresh $\mathrm{SiO}_{2} \mathrm{sol}$, we achieved the lowest wettability of the composite surface, i.e. the water contact angle was $123^{\circ}$. The non-aqueous solution based on PFOTEOS and the solution with hexadecyltriethoxysilan (HDTEOS) and $\mathrm{SiO}_{2}$ sol also led to high contact angles of the impregnated composites, $98^{\circ}$ and $105^{\circ}$ respectively. The presence of $\mathrm{SiO}_{2}$ sol was found to be crucial as worse results were obtained when the impregnation in the solution without it was used. In principle, the modification was done by attaching hydrophobic group by $\mathrm{SiO}_{2}$ nanoparticles on the surface and into the inner structure of the geopolymer. It was confirmed by water uptake test that water did not influence the contact angle values; the storage modulus characterizing the stiffness of the composite slightly decreased. The amount of water absorbed by the composite was in the range of 3.2 to $4.3 \%$ regardless of the treatment. This means that the treatment is a hydrophobic impregnation, which does not affect pores, i.e. acts only as a water repellent.

\section{ACKNOWLEDGEMENTS}

This result was obtained within the institutional support of the Ministry of Industry and Trade of the Czech Republic for the development of a research organization (decision No. 12/2017).

\section{REFERENCES}

[1] Davidovits J. (2011). Geopolymer Chemistry and Applications, 3rd ed. Institute Géopolymère. ISBN: 9782951482050

[2] International standard EN 1504-2:2004. Products and systems for the protection and repair of concrete structures - Definitions, requirements, quality control and evaluation of conformity - Part 2: Surface protection systems for concrete 
[3] Nurhan O. et al. (2015): Water-and Oil-Reppelency properties of Cotton Fabric Treated with Silane. International Journal of Textile Science, 4(4), 84-96. DOI:10.5923/j.textile.20150404.03

[4] Zhang H., Liu Q., Liu T., Zhang B. (2000): The preservation damage of hydrophobic polymer coating materials in conservation of stone relics. Progress in Organic Coatings, 76,1127-34. DOI:10.1016/j.porgcoat.2013.03.018

[5] Duan P., Yan Ch., Luo W., Zhou W. (2016): A novel surface waterproof geopolymer derived from metakaolin by hydrophobic modification, Materials Letters 164, 172-175. doi: 10.1016/j.matlet.2015.11.006

[6] Mahltig B., Böttcher H. (2003): Modified Silica Sol Coatings for Water-Repellent Textiles. Journal of Sol-Gel Science and Technology 27(1), 43-52. DOI:10.1023/A:1022627926243

[7] Daoud W.A., Xin J.H., Tao X. (2004):

Superhydrophobic Silica Nanocomposite Coating by a
Low-Temperature Process. Journal of the American Ceramic Society 87, 1782-1784. DOI:10.1111/j.1551-2916.2004.01782.x

[8] Daoud W.A., Xin J.H., Tao X. (2006): Synthesis and characterization of hydrophobic silica nanocomposites. Applied Surface Science 252, 5368-5371. DOI:10.1016/j.apsusc.2005.12.020

[9] Daoud W.A., Xin J.H., Zhang Y.H., Mak C.L. (2006): Pulsed laser deposition of superhydrophobic thin Teflon films on cellulosic fibers. Thin Solid Films 515, 835-837. DOI:10.1016/j.tsf.2005.12.245

[10] Hongxia W. et al (2017): Durable, self-healing, superhydrophobic fabrics from fluorine-free, waterborne, polydopamine/alkyl silane coatings, RSC Advances, 7, 33986-33993. DOI:10.1039/C7RA04863G

[11] E. I. DU PONT DE NEMOURS AND COMPANY. Binder for Zink-Rich paint. Inventor: Aaron Oken. IPC C09D 5/10. US3649307, 14.03.1972, WIPO. 